\title{
Preconditioning of the 2007 sea-ice melt in the eastern Beaufort Sea, Arctic Ocean
}

\author{
Jennifer K. HUTCHINGS, ${ }^{1}$ Donald K. PEROVICH ${ }^{2}$ \\ ${ }^{1}$ College for Earth, Ocean and Atmospheric Science, Oregon State University, Corvallis, OR, USA \\ E-mail: jhutchings@coas.oregonstate.edu \\ ${ }^{2}$ US Army Cold Regions Research and Engineering Laboratory, Hanover, NH, USA
}

\begin{abstract}
During summer 2007, perennial sea ice in the Beaufort Sea, Arctic Ocean, experienced an unprecedented amount of basal melt. It has previously been shown that this basal melt was linked to an increase in open-water fraction, increasing absorption of solar radiation into the ocean. GPS ice drifters, deployed around the site where the unprecedented basal melt was observed, provide a coincident observation of local divergence. This divergence is used to drive a multi-thickness category thermodynamic sea-ice model. We demonstrate that $\sim 75 \%$ of the observed open-water fraction by midsummer 2007 can be attributed to ice pack divergence during the growth season, preconditioning the ice pack for early melt in summer. Divergence during the melt season explains the remaining $25 \%$ of open water. Enhanced ice pack divergence in spring and summer 2007, in response to the increased transport of ice out of the Beaufort Sea, was sufficient to explain the melt observed in summer 2007 and the heat stored in the upper ocean at the end of summer.
\end{abstract}

KEYWORDS: sea-ice dynamics

\section{INTRODUCTION}

In summer 2007, basal melt of $2.1 \mathrm{~m}$ was recorded for multiyear (MY) ice at a drifting ice mass balance (IMB) site in the eastern Beaufort Sea, Arctic Ocean (Perovich and others, 2008). This is close to four times the previously observed summer melt in this region. There was no evidence that incoming solar radiation increased over the Beaufort Sea (Schwieger and others, 2008). Perovich and others (2008) demonstrated that the melt could be explained by heating of the upper ocean from available incoming solar radiation incident on open water around the IMB site. The ice concentration in the region was low in summer 2007 compared to previous years; however, the controls of this reduced ice area were not explored by Perovich and others (2008). Essentially the ice-albedo feedback that resulted in the 2007 ice melt required a trigger of enhanced solar input to the upper ocean in early summer.

There are several ways to enhance solar input into the upper ocean, that are related to observed changes to the Beaufort ice pack. Increases in melt season length (Markus and others, 2009), especially earlier melt onset, have led to enhanced solar absorption in the upper-ocean ice system (Perovich and others, 2011). Itoh and others (2011) found that increasing area of melt ponds on the ice could explain some of the increased solar heat flux to the ocean and ice base. The Arctic ice pack is younger, and therefore thinner, in the 2000s than in the previous three decades (Maslanik and others, 2007). This thinning in the Beaufort Sea has been related to enhanced transpolar ice-drift rates (Hutchings and Rigor, 2012). A thinner ice pack will melt faster in summer, increasing open water and enhancing ice-albedo feedback. An observed increase in oceanic heat transport through the Bering Strait has been suggested to be a trigger for the enhanced ice melt, and ice-albedo feedback, in summer 2007 (Woodgate and others, 2010). This mechanism for early onset of ice melt would occur along the pathways of Pacific Water in the Chukchi and western Beaufort Seas, and may not be as important at the IMB site in the Beaufort Sea case study of Perovich and others (2008).

Another mechanism that has not been explored for the summer 2007 Beaufort Sea melt is enhanced divergence of the ice pack. Rampal and others (2009) found that sea-ice deformation rates, shear plus divergence, throughout the Arctic have increased. This indicates changes in divergence rates that would drive changes in open-water fraction, ridging and ice growth. Changes in the mechanical properties of the ice pack (e.g. weakening through thinning) can act to either enhance albedo feedback (through increased opening and increasing area of thin ice or open water) or retard ice loss as increasing convergence-driven ridging and rafting increases ice volume. To understand the role of sea-ice deformation in the recently documented ice loss in the Beaufort Sea, observations of ice pack divergence are required. Regional and global sea-ice models have been shown to not perform adequately in simulating sea-ice divergence (Kwok and others, 2008; Rampal and others, 2011).

In this paper, we explore the role of ice pack divergence in modifying the open-water fraction at the location of observed ice melt. We use a model, driven by observed ice pack divergence, to partition the impact of dynamic (opening and ridging) and thermodynamically (ice growth/ melt) driven ice area changes on summer melt. Observations of ice pack deformation were made with GPS ice drifters in a $\sim 30 \mathrm{~km}$ region around the IMB buoy. Time series of buoy positions were analyzed to provide divergence rate in the vicinity of the IMB buoy, which were then used to drive a multi-thickness category model of ice growth, melt and redistribution. In the following section we introduce the GPS data used in this study, the model is then outlined and finally we present the conclusions of our investigation and discussion. 


\section{ANALYSIS OF DRIFTING-BUOY DATA}

Enhanced divergence in winter increases ice growth, as wintertime ice pack divergence occurs through lead or polynya opening. To estimate this growth rate and ridging rates, synoptic events must be resolved (Hutchings and others, 2011). Tracking sea-ice strain rate such that synoptic timescales are resolved is possible with GPS drifters on spatial scales greater than a few kilometers.

An array of six such drifters was deployed on 5 September 2006 in the northeastern Beaufort Sea, forming a ring with radius $16 \mathrm{~km}$ around buoy $2006 \mathrm{C}$, the IMB buoy that experienced dramatic melt in summer 2007 (Perovich and others, 2008). The array drifted south in the following winter and summer (Fig. 1). The buoys reported position every $10 \mathrm{~min}$, and have a relative position accuracy of $\pm 2 \mathrm{~m}$ (Hutchings and others, 2012).

From the $10 \mathrm{~min}$ positions provided by the six GPS drifters, area and divergence rate are calculated hourly following the method of Hutchings and others (2012). The buoy array became highly skewed in mid-July 2007, making area and divergence calculation inaccurate. Hence we do not consider model results past mid-July 2007 in our discussion. The error on area calculation is estimated to be $<1 \%$ (following Hutchings and others, 2012).

\section{MODEL OF FIRST-YEAR ICE GROWTH, RIDGING AND MELT}

A model of first-year (FY) ice growth and ridging is used to investigate the effect of ice pack divergence on the area and mean thickness of FY ice entering summer, and melt during summer.

A time series of area for the buoy array (Fig. 2) was calculated following Hutchings and others (2012). The area within the buoy array is estimated using Green's theorem $\oint \mathrm{d} A=\iint(x \mathrm{~d} y-y \mathrm{~d} x)$, at hourly intervals from linearly interpolated $10 \mathrm{~min}$ buoy position when all six buoys were operating. This line integral is discretized as

$$
A \approx \frac{1}{2} \sum_{n=0}^{N}\left(x^{n} y^{n+1}-y^{n} x^{n+1}\right)+x^{N} y^{0}-y^{N} x^{0} .
$$

where $x$ and $y$ are buoy positions projected onto a Lambert equal-area map.

From the date of buoy deployment, 6 September, we calculate the area of open water $L$ within the region $A$ at hourly time steps $t$,

$$
L^{t}=\max \left(A^{t}-A^{t-1}, 0\right) .
$$

We track the thickness distribution of ice that grows in this open water through the winter and into summer. The FY ice thickness distribution is approximated as a 20-level histogram with thickness categories $0.5 \mathrm{~m}$ apart, where we track area and mean thickness of the ice in each category. At the start of each time step $t$ we add the area of open water formed, $L^{t}$, to the $0-0.5 \mathrm{~m}$ category. We calculate the growth or melt of ice in each category by applying growth rates from a look-up table of Maykut and Untersteiner (1971). If the ice in a category becomes larger (or smaller) than the category's upper (lower) thickness bound, it is combined into the category above (below), adjusting mean thickness and area of both categories accordingly. We use the terms growth season and melt season in our discussion, which are

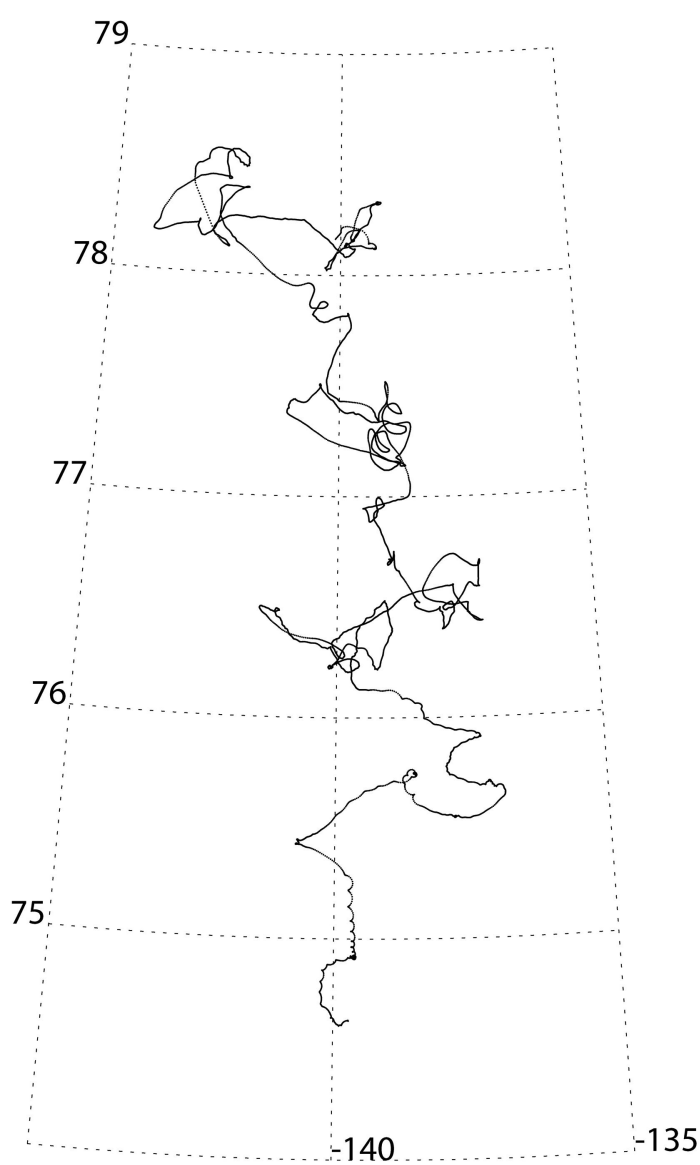

Fig. 1. Drift track of the centroid of buoys deployed from 5 September 2006 to mid-July 2007. Buoys drifted south in the eastern Beaufort Sea.

defined by the model as being before and after (respectively) the date at which first melt occurs for the thinnest ice.

We calculate ridged ice volume at the end of each time step. On closing, $A^{t}-A^{t-1}<0$, the area of ridged ice $R$ is

$$
R=\max \left(A^{t-1}-A^{t}, 0\right) .
$$

The assumption is made that thin ice is ridged preferentially. The ridged ice volume $R$ is calculated as

$$
R_{\mathrm{v}}=\sum_{i=0}^{20} h_{i}\left(a_{i}-\max \left\{\min \left[\left(R-\sum_{j=0}^{i} a_{j}\right), a_{i}\right], 0\right\}\right),
$$

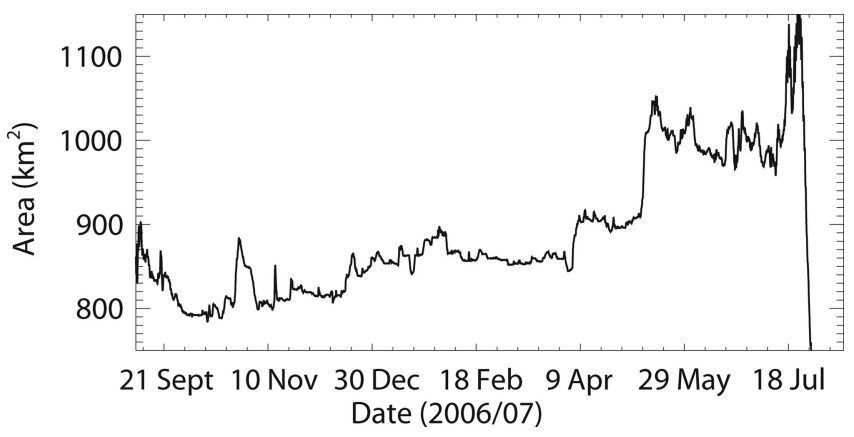

Fig. 2. Area within the array of six GPS buoys deployed around IMB buoy 2006C. Note that in mid-July the buoy array sheared, with area reducing and becoming too small for accurate divergence calculation. 
where $h$ is the mean ice thickness and a the area of the thickness categories $i=0,1 \ldots 20$. The area of all categories from which ice was ridged is adjusted accordingly after ridging volume is calculated.

The thermodynamic rates of change of ice thickness do not account for lateral melt, and were based on field experiments investigating one-dimensional heat budget in the perennial ice pack in the 1960s (Maykut and Untersteiner, 1971). It is possible the growth rates in the 1960s were higher than current conditions, which may have increased oceanic heat flux to the bottom of the ice. Summer melt rates should be regarded with caution, as solar input to the upper ocean (which may have increased over the past decade (Kay and others, 2008)) and lateral melt are considered important in determining melt rates. We expect our model overestimates FY ice thickness entering summer and underestimates the rate of FY ice melt during summer.

In reality, ice from all parts of the thickness distribution is ridged during individual closing events, and more sophisticated ridging models account for this with a redistribution function that includes a distribution of level ice lost during ridging (Rothrock, 1975). Our simplification of the distribution of ridged level ice will result in lower end-of-winter areas of FY ice on the thin side of the FY ice thickness probability distribution function. Hence we expect our model results in an overestimate of the mean FY ice thickness entering summer. The area of FY ice entering summer could be slightly underestimated, as we do not allow MY ice to ridge in our model when FY ice is present. In summary, this model provides a lower estimate of the open-water fraction during summer.

\section{MODEL RESULTS}

From 6 June to 15 October 2007, close to $2.1 \mathrm{~m}$ of basal ice melt was observed at the IMB 2006C site, which could be explained by solar radiation absorption through open water in the vicinity of the IMB buoy (Perovich and others, 2008). Their estimate of the open-water fraction was from passive microwave ice concentration estimates. We investigate whether observed ice pack divergence led to the increased open-water area in summer 2007, causing the enhanced solar absorption Perovich and others (2008) estimated.

The model, described above, of FY ice growth and ridging is driven by the divergence calculated from driftingbuoy positions. With this model we track open-water fraction during winter 2006/07 and summer 2007 (Fig. 3a, red line). The modeled ice concentration is comparable to that of the AMSR-E (Advanced Microwave Scanning Radiometer for Earth Observing System) NASA Team ice concentration (Cavalieri and others, 2004; Fig. 3a, orange line) in the vicinity of the IMB buoy, and is slightly lower than the passive microwave open-water estimates used in Perovich and others (2008). There are some differences: for example, the model does not show a decrease in ice concentration at the start of summer, though this may be an artifact of surface wetting in the passive microwave ice concentration estimate (Cavalieri and others, 1990).

The open water in the model is attributed to melt of FY ice, which was formed during divergence events in winter 2006/07, and divergence of the ice pack during the melt season. In the following discussion, we use the ability of our model to reproduce the trend in open water during summer 2007 to identify the partitioning of this open-water fraction
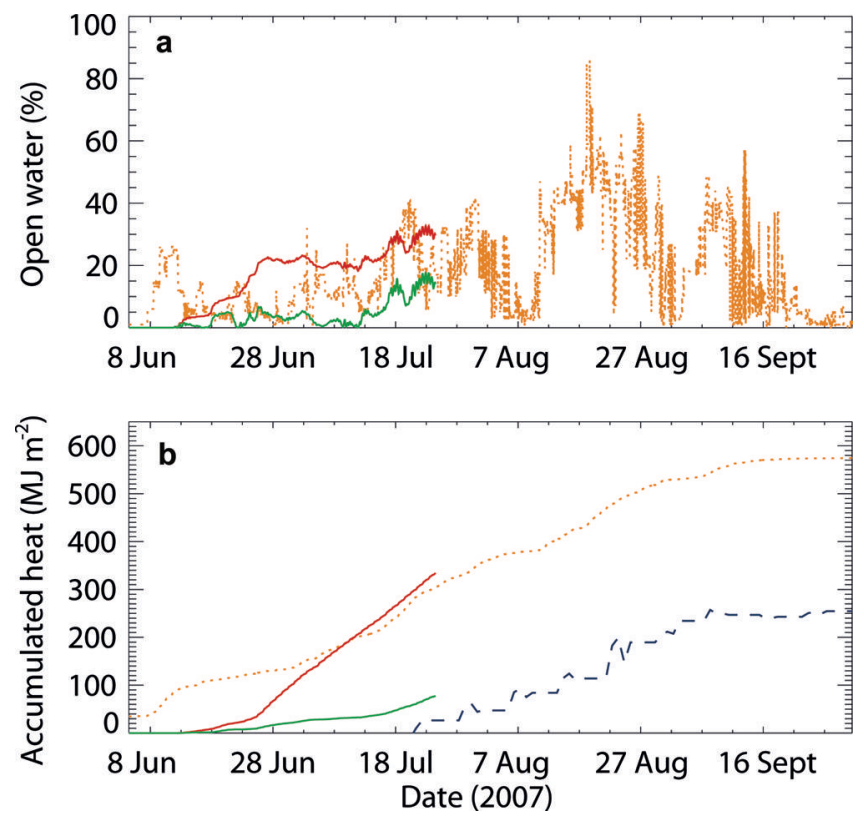

Fig. 3. (a) Open-water percentage from AMSR-E (orange dotted line), open water from a model of thermodynamic ice growth/melt and ridging (red line) and open water due to divergence during the melt season (green line). (b) Accumulated heat input into the ocean through open water, with estimates from AMSR-E (orange dotted line), modeled open water (red line) and opening due to divergence in melt season (green line). Heat required for basal melt to date in the melt season is shown as a blue dashed line.

between in situ ice melt and divergence of the ice pack during the melt season.

We can calculate the amount of opening that is due to divergence alone, and not ice melt, by tracking array area change since the onset of melt. About one-quarter of the observed open water in summer 2007 can be attributed to summer ice pack divergence (Fig. 3b, green line). The other three-quarters is due to melt of FY ice. We find that level ice that formed later in the growth season, during divergence events around early April and mid-May (Fig. 2), melts early in summer. These divergence events contributed to decreased ice area in the following summer, and would have preconditioned the ice pack for enhanced melt.

We estimate solar radiation flux into the ocean through open water as

$$
F_{\mathrm{O}}=(1-\alpha) L F_{\mathrm{S}},
$$

where $\alpha=0.07$ is the albedo of open water (Pegau and Paulson, 2001), $F_{\mathrm{S}}$ is downwelling shortwave radiation at the surface from European Centre for Medium-Range Weather Forecasts (ECMWF) ERA-Interim reanalysis 3 hour forecasts and $L$ is the open-water fraction. Figure $3 b$ shows accumulated $F_{\mathrm{O}}$ for open water estimated from AMSR-E (orange), our model (red) and summer ice divergence alone (green). We calculate a similar accumulation of solar heat, through openwater fraction provided by AMSR-E and our model.

The amount of heat in basal melt is estimated following Perovich and others (2008). We assume that the basal melt observed at the IMB site is representative of basal melt in the vicinity of the site, such that the heat used in melting ice in a unit area of this region is

$$
F_{\mathrm{L}}=\rho_{\mathrm{i}} L_{\mathrm{H}} L \frac{\partial z}{\partial t},
$$


where ice density $\rho_{\mathrm{i}}=917 \mathrm{~kg} \mathrm{~m}^{-3}$, latent heat of fusion $L_{H}=333400 \mathrm{~J} \mathrm{~kg}^{-1}$ and the rate of basal ice melt, $\frac{\partial z}{\partial t^{\prime}}$ is provided by daily acoustic measurements of distance to the underside of the ice at the IMB site. Like Perovich and others (2008) we find that double the heat required to explain the observed basal melt is provided by solar warming at open water. The excess heat not used in basal ice melt would contribute to lateral ice melt and heat storage in the upper ocean. During the first half of the melt season our model demonstrates that this open-water fraction was primarily due to the melt of FY ice. Until mid-July the majority of the enhanced solar heating of the upper ocean in 2007 can be explained by ice pack divergence during the 2006/07 growth season, with opening late in the season, and divergence during summer 2007 played a smaller, yet significant role. Analysis of International Arctic Buoy Programme buoy drift throughout the Beaufort Sea indicates that the magnitude of opening in 2007 was four times that observed between 2000 and 2006 (Hutchings and others, 2012).

\section{DISCUSSION}

Our model demonstrates that the divergence of the ice pack in the vicinity of a drifting IMB buoy 2006C can explain the observed basal melt. Both divergence in winter, creating FY ice that melts out in summer, and divergence in summer contributed to the observed melt. However, both mechanisms, considered alone, provide sufficient solar warming of the upper ocean to explain the observed basal melt. The excess heat provided to the upper ocean is used in lateral ice melt, some is stored in the upper ocean which could reduce ice growth rates following summer, and some is lost to the atmosphere through increased longwave and turbulent fluxes.

Changes in the Beaufort ice pack since 2006 coincide with observed changes in the upper ocean including a temperature maximum near the base of the mixed layer that is associated with solar absorption into the upper ocean and ice-melt driven near-surface stratification (Jackson and others, 2010). Steele and others (2010) demonstrate that this temperature maximum is mostly due to enhanced solar absorption in the increasing area of open water in the Beaufort, and the stored heat is $<20 \%$ of the observed melt in summer 2007 (Steele and others, 2011). Solar energy absorbed in the upper ocean that is not used in basal ice melt, lateral ice melt or released back to the atmosphere as longwave radiation and sensible heat contributes to the creation of the near-surface temperature maximum (NSTM) that perpetuated into winter 2007/08 (Jackson and others, 2010). As the heat content of this NSTM layer is less than the heat used in IMB 2006C observed basal melt, divergence of the ice pack is sufficient to explain both ice melt and upperocean heating for this case study in the eastern Beaufort Sea in summer 2007.

Lateral melt and ocean-to-atmosphere heat fluxes are not considered in our study, as we do not have observations with which to estimate these. The volume of lateral melt has been estimated to be comparable to that of basal melt; the ratio of lateral to basal melt volume has been observed to be as large as 3:5 in leads (Perovich and others, 2003), and it increases as floe size decreases during the progression of melt in the marginal ice zone (Steele, 1992). Longwave emission from the ocean surface increases due to the increasing temperature with higher open-water fraction.
Sensible and latent heat fluxes might also increase due to enhanced exposure of water to the atmosphere. However, these heat losses from the ocean may be offset by related changes in the atmosphere such as increasing downward longwave radiation fluxes. We estimate $40 \%$ of the incoming solar radiation absorbed by open water in summer 2007 was used in lateral melt and to offset changes in the surface energy budget.

It is not possible to close the full energy budget for the region of our field experiment; however, we can draw some inferences regarding the energy budget in the region for summer 2007. Solar radiation input to the upper ocean can explain the unprecedented large basal ice melt observed in the eastern Beaufort Sea. The enhanced solar radiation input during summer 2007 is due to preconditioning of the pack for melt by enhanced divergence late in the growth season. Increase in solar energy input to the upper ocean continued through summer at the same rate as observed in the first half of summer (Fig. 3, dotted orange lines showing estimate from AMSR-E open water). A steady rate of solar heat accumulation in the upper ocean suggests ice meltout and divergence rates accelerated through the summer as downwelling solar radiation decreased into August. Our driftingbuoy data demonstrate there may have been enhanced divergence at the buoy location, with increased rate of open-water formation in early summer, yet we estimate a similar heat budget to that estimated with wider-area passive microwave concentration. Unfortunately we were unable to monitor ice divergence through the whole summer, though we might infer, given the nature of ice-albedo feedback, that rates of heat accumulation would follow or be greater than (locally) the AMSR-E estimate. We can expect the solar energy absorbed in the upper ocean also resulted in enhanced lateral ice melt. If this ice volume loss was similar in magnitude to basal ice melt, it is possible that an additional heat source is required to explain the increased heat storage in the upper ocean and volume of melt.

To better quantify the relative partitioning of incoming solar radiation at the ice/ocean surface between ice melt, ocean heat storage and radiative and sensible heating of the atmosphere requires observations that are not available in this case study. Solar heating through the ice and melt ponds increases the available energy. It is possible to model the contribution of this if one knows the melt pond fraction, or can model the evolution of melt pond fraction based on the initial ice thickness and snow distribution. This was not attempted in our case study, as the initial distributions were unknown. Melt ponds would contribute to provide additional solar warming of the ice and upper ocean over and above the lower estimate of solar absorption through open water our model provides. The volume of basal ice melt in an area of variable ice thickness is not easily monitored, but can be linked to initial measured thickness distribution of the ice through a thermodynamic model. Lateral ice melt can also be modeled given knowledge of the full ice thickness distribution and seasonal progression of floe size. Unfortunately this was not measured, so we did not include the melt of MY ice or lateral melt in our model. The conclusion we can draw is that divergence in the eastern Beaufort Sea during winter 2006/07 provided sufficient preconditioning to explain observed MY basal melt observed at a point in the region. This indicates the need to improve the representation of wintertime ice pack divergence in sea-ice models. 


\section{ACKNOWLEDGEMENTS}

We thank Captain McNeil and the crew of the Louis $S$. St Laurent, who enabled in situ ice observation and buoy deployments in the Beaufort Sea. Satellite passive microwave sea-ice concentration, AMSR-E products, were provided by the US National Snow and Ice Data Center. The European Centre for Medium-Range Weather Forecasts (ECMWF) provided data from the ECMWF reanalysis, ERA-Interim. The GPS drifting buoys deployed in 2006 were funded by the US National Science Foundation (NSF) ARC 0520574, and further analysis funded through NSF AON 1023662. Hutchings was supported by grants to the University of Alaska Fairbanks, International Arctic Research Center (ARC) from the Japan Agency for Marine-Earth Science and Technology (JAMSTEC) under the JAMSTEC and IARC Collaboration Studies and the Japan Aerospace Exploration Agency (JAXA) under the Arctic Research Plan Utilizing the IARC-JAXA Information System (IJIS) and Satellite Imagery. Perovich was supported by the Arctic Observing Network, NSF. We thank two reviewers and the editors, Ken Golden and Petra Heil, who improved the clarity of the manuscript.

\section{REFERENCES}

Cavalieri D, Burns BA and Onstott RG (1990) Investigation on the effects of summer melt on the calculation of sea ice concentration using active and passive microwave data. J. Geophys. Res., 95(C4), 5359-5369

Cavalieri DJ, Markus T and Comiso J (2004) AMSR-E/Aqua Daily L3 $12.5 \mathrm{~km}$ Brightness Temperature, Sea Ice Concentration, and Snow Depth Polar Grids, V002, 2006 to 2007, updated daily. National Snow and Ice Data Center, Boulder, CO. Digital media: nsidc.org/data/ae_si12

Hutchings JK and Rigor IG (2012) Role of ice dynamics in anomalous ice conditions in the Beaufort Sea during 2006 and 2007. J. Geophys. Res., 117(C8), C00E04 (doi: 10.1029/ 2011JC007182)

Hutchings JK, Roberts A, Geiger C and Richter-Menge J (2011) Spatial and temporal characterization of sea-ice deformation. Ann. Glaciol., 52(57 Pt 2), 360-368 (doi: 10.3189/ 2011AoG57A185)

Hutchings JK, Heil P, Steer A and Hibler WDI (2012) Sub-synoptic scale spatial variability of sea ice deformation in the western Weddell Sea during early summer. J. Geophys. Res., 117(C1), C01002 (doi: 10.1029/2011JC006961)

Itoh $M$ and 7 others (2011) Acceleration of sea-ice melting due to transmission of solar radiation through ponded ice area in the Arctic Ocean: results of in situ observations from icebreakers in 2006 and 2007. Ann. Glaciol., 52(57 Pt 2), 249-260 (doi: 10.3189/172756411795931471)

Jackson JM, Carmack EC, McLaughlin FA, Allen SE and Ingram RG (2010) Identification, characterization, and change of the nearsurface temperature maximum in the Canada Basin, 19932008. J. Geophys. Res., 115(C5), C05021 (doi: 10.1029/ 2009JC005265)

Kay JE, L'Ecuyer T, Gettelman A, Stephens G and O'Dell C (2008) The contribution of clouf and radiation anomalies to the 2007
Arctic sea ice extent minimum. Geophys. Res. Lett., 35(8), L08503 (doi: 10.1029/2008GL033451)

Kwok R, Hunke EC, Maslowski W, Menemenlis D and Zhang J (2008) Variability of sea ice simulations assessed with RGPS kinematics. J. Geophys. Res., 113(C11), C11012 (doi: 10.1029/ 2008JC004783)

Markus T, Stroeve JC and Miller J (2009) Recent changes in Arctic sea ice melt onset, freezeup, and melt season length. J. Geophys. Res., 114(C12), C12024 (doi: 10.1029/2009JC005436)

Maslanik JA, Fowler C, Stroeve J, Drobot S and Zwally HJ (2007) A younger, thinner Arctic ice cover: increased potential for rapid, extensive ice loss. Geophys. Res. Lett., 34(24), L24501 (doi: 10.1029/2007GL032043)

Maykut GA and Untersteiner N (1971) Some results from a timedependent thermodynamic model of sea ice. J. Geophys. Res., 76(6), 1550-1575 (doi: 10.1029/JC076i006p01550)

Pegau WS and Paulson CA (2001) The albedo of Arctic leads in summer. Ann. Glaciol., 33, 221-224 (doi: 10.3189/ 172756401781818833)

Perovich DK, Grenfell TC, Richter-Menge JA, Light B, Tucker WB III and Eicken $\mathrm{H}$ (2003) Thin and thinner: ice mass balance measurements during SHEBA. J. Geophys. Res., 108(C3), 8050 (doi: 10.1029/2001JC001079)

Perovich DK, Richter-Menge JA, Jones KF and Light B (2008) Sunlight, water, and ice: extreme Arctic sea ice melt during the summer of 2007. Geophys. Res. Lett., 35(11), L11501 (doi: 10.1029/2008GL034007)

Perovich DK and 6 others (2011) Solar partitioning in a changing Arctic sea-ice cover. Ann. Glaciol., 52(57 Pt 2), 192-196 (doi: 10.3189/172756411795931543)

Rampal P, Weiss J and Marsan D (2009) Positive trend in the mean speed and deformation rate of Arctic sea ice, 19792007. J. Geophys. Res., 114(C5), C05013 (doi: 10.1029/ 2008JC005066)

Rampal P, Weiss J, Dubois C and Campin J-M (2011) IPCC climate models do not capture Arctic sea ice drift acceleration: consequences in terms of projected sea ice thinning and decline. 116(C8), C00D07 (doi: 10.1029/2011JC007110)

Rothrock DA (1975) The energetics of the plastic deformation of pack ice by ridging. J. Geophys. Res., 80(33), 4514-4519 (doi: 10.1029/JC080i033p04514)

Schwieger AJ, Zhang J, Lindsay RW and Steele M (2008) Did unusually sunny skies help drive the record sea ice minimum of 2007? Geophys. Res. Lett., 35(10), L10503 (doi: 10.1029/ 2008GL033463)

Steele M (1992) Sea ice melting and floe geometry in a simple iceocean model. J. Geophys. Res., 97(C11), 17 729-17 738 (doi: 10.1029/92JC01755)

Steele M, Zhang J and Ermold W (2010) Mechanisms of summertime upper Arctic Ocean warming and the effect on sea ice melt. J. Geophys. Res., 115(C11), C11004 (doi: 10.1029/ 2009JC005849)

Steele M, Ermold W and Zhang J (2011) Modeling the formation and fate of the near-surface temperature maximum in the Canadian Basin of the Arctic Ocean. J. Geophys. Res., 116(C11), C11015 (doi: 10.1029/2010JC006803)

Woodgate RA, Weingartner T and Lindsay R (2010) The 2007 Bering Strait oceanic heat flux and anomalous Arctic sea-ice retreat. Geophys. Res. Lett., 37(1), L01602 (doi: 10.1029/ 2009GL041621) 